\title{
COMPREENSÃO DE DOCENTES DOS CURSOS DE GRADUAÇÃO EM CIÊNCIAS CONTÁBEIS ACERCA DA ESTRUTURA CONCEITUAL BÁSICA
}

\author{
I. F LEITE ${ }^{1}$, A. R. AXIOLE ${ }^{2}$, C. L. L. MELO ${ }^{3}$, E. R. F. C. V. LUCENA ${ }^{4}$ \\ 1,2,3,4 Universidade Federal do Rio Grande do Norte \\ igorfleitee@gmail.com ${ }^{1}$
}

Submetido 31/05/2017 - Aceito 03/02/2018

DOI: $10.15628 /$ holos. 2018.5965

\begin{abstract}
RESUMO
O presente trabalho teve como objetivo medir o nível de conhecimento de docentes de ciências contábeis de programas de graduação do estado do Rio Grande do Norte sobre a estrutura conceitual básica. A metodologia do trabalho se caracteriza como descritivaquantitativa. Para tanto, foi elaborado um questionário online em escala Likert de cinco pontos, que foi enviado para 89 docentes. Desses, 32 responderam de forma completa. Os procedimentos estatísticos utilizados para analisar a relação entre as variáveis foram o teste de Kolmogorov-Smirnov e Shapiro-Wilk para testar normalidade, teste de Kruskal-Wallis para buscar possíveis diferenças de médias e a correlação para
\end{abstract}

observar se existe relação entre a variável dependente e as variáveis independentes. Como resultado, destaca-se que o nível de conhecimento dos docentes sobre a estrutura conceitual é considerado alto. A importância da estrutura conceitual e a frequência que o assunto deve ser discutido em sala de aula são consideradas altas, por parte dos docentes. Ainda assim, 69\% dos entrevistados nunca realizou pesquisas relacionadas à estrutura. Além disso, o nível de conhecimento dos docentes sobre o assunto não varia de acordo com a região, instituição de ensino (pública ou privada) e disciplinas que lecionam.

PALAVRAS-CHAVE: Contabilidade, Estrutura Conceitual, Nível de compreensão.

\section{KNOWLEDGE LEVEL OF THE PROFESSORS OF UNDERGRADUATE COURSES IN ACCOUNTING SCIENCE ABOUT THE BASIC CONCEPTUAL FRAMEWORK}

\begin{abstract}
This article had as objective to measure the level of knowledge of Accounting teachers of undergraduate programs of the state of Rio Grande do Norte on the basic conceptual structure. The methodology of the work is characterized as descriptive-quantitative. For that, an online questionnaire was drawn up on a fivepoint Likert scale, which was sent to 89 teachers. Of these, 32 responded completely. The statistical procedures used to analyze the relationship between variables were the Kolmogorov-Smirnov and ShapiroWilk test for normality test, Kruskal-Wallis test for possible mean differences and correlation to observe if
\end{abstract}

there is a relationship between the dependent variable and the independent variables. As a result, it is emphasized that the level of knowledge of the teachers about the conceptual structure is considered high. The importance of the conceptual structure and the frequency that the subject should be discussed in the classroom are considered high by the teachers. Nevertheless, $69 \%$ of the interviewees never carried out research related to the structure. Besides that, the level of knowledge of the teachers on the subject does not vary according to the region, educational institution (public or private) and subjects that teach.

KEYWORDS: Accounting. Conceptual Framework. Knowledge level 


\section{INTRODUÇÃO}

$\mathrm{Na}$ última década, a contabilidade esteve no centro de uma série de transformações estruturais, que fizeram com que todas os usuários envolvidos com esta ciência mudassem suas antigas concepções e tivessem que ampliar seus conhecimentos a respeito da área (Fernandes, Lima, Vieira \& Niyama, 2011). As transformações ocorridas na ciência contábil foram oriundas da necessidade do mercado financeiro, que passou por um processo de globalização dos negócios, grande competitividade empresarial internacional, e a necessidade da mobilidade de investimentos para o sistema capitalista, com o propósito de buscar melhores alternativas de ganhos (Beck \& Rausch, 2014).

Tal cenário econômico internacional exigiu da ciência contábil uma busca por um padrão único objetivando a comparabilidade das demonstrações financeiras das empresas que desempenham suas atividades em vários países e se utilizam da captação de recursos no mercado internacional de capitais. Dessa forma, teve início a harmonização contábil e a busca da aproximação das normas contábeis internacionais que têm como objetivo reduzir as diversidades pertinentes às práticas de reconhecimento, mensuração e evidenciação das informações contábeis dos diversos países (Fernandes et al., 2011).

Com a convergência das normas internacionais de contabilidade, no Brasil, em 2008, foi emitido e aprovado o Pronunciamento Conceitual Básico - Estrutura conceitual para elaboração e apresentação das demonstrações contábeis, o CPC 00, que teve sua primeira revisão no ano de 2011, pronunciamento correlato com o Framework for the Preparation and Presentation of Financial Statements, do International Accounting Standards Board (IASB).

Para Gilio \& Afonso (2013), a adoção às normas internacionais contribuiu para aproximação entre as práticas da contabilidade financeira (focada no usuário externo) e a contabilidade gerencial (focada no usuário interno). Frezatti, Braga de Aguiar\& Guerreiro (2007) retratam que a contabilidade financeira e a gerencial se utilizam da contabilidade como fonte básica no processo decisório, mas não necessariamente da mesma forma. Wirtanen (2009) afirmou que as normas internacionais influenciam as práticas e as maneiras de analisar e interpretar as informações contábeis gerenciais. A pesquisa de Domingos de Araújo, Cornacchione Junior, Reginato \& da Silva Suzart (2014) mostrou que há impactos das normas internacionais na contabilidade gerencial. Assim, percebe-se que é necessário para o usuário interno o conhecimento sobre as normas internacionais.

Nesse sentido, o contexto da educação contábil, que surgiu de uma filosofia code law e da influência das normas fiscais e do governo na contabilidade societária, para uma abordagem baseada em princípios, julgamentos e subjetivismo responsável, apresenta mudança fundamental que precisa ocorrer no processo de ensino aprendizagem brasileiro, sendo o docente o responsável pela disseminação desses preceitos (Carvalho \& Salotti, 2013; Nunes et al, 2016). Ensinar e adequar, portanto, os futuros profissionais da contabilidade aos novos métodos é uma experiência desafiadora, a ponto de ser necessária forte fundamentação teórica para aderir aos processos de conversão (Lopes, 2011).

A importância da estrutura conceitual básica da contabilidade se deve que na estrutura se estabelece os conceitos que fundamentam a elaboração e divulgação das demonstrações contábeis que são destinados aos diversos usuários (Comitê, 2011). Para Cruz, Ferreira \& Szuster (2011) a estrutura conceitual foca principalmente no que tange ao julgamento profissional, capacidade de interpretação e ao comprometimento com a melhor evidenciação. 
Gil (2006) define que, de modo geral, o professor universitário ou de qualquer outro nível da educação necessita de um sólido e atualizado conhecimento na área em que pretende atuar (Pavione; Avelino \& Francisco, 2016). Assim, o ensino das International Financial Reporting Standards (IFRS) deve auxiliar os futuros profissionais no desenvolvimento dessa capacidade de auxiliar na tomada de decisões e na indicação de métodos a serem traçados nos negócios (Espejo, Costa, Espejo \& Comunelo, 2010).

Um dos desafios encontrado pelos docentes é o de desenvolver um senso crítico nos alunos que permita a eles criar e defender suas próprias escolhas, baseadas na estrutura conceitual da contabilidade (Jackling, Howieson \& Natoli, 2012). Mesmo diante dos desafios gerados pelas mudanças nas práticas contábeis de regras para princípios, o ensino da estrutura conceitual pode ajudar a melhorar a educação contábil e, consequentemente, a valorização desses profissionais (Hodgon, Hughes \& Street, 2011).

Nessa perspectiva, a adoção das IFRS pelo Brasil, a função relevante dos conceitos apresentados na estrutura conceitual no ensino da contabilidade e na elaboração dos relatórios contábeis financeiros, a necessidade da educação continuada dos docentes que atuam na formação e especialização dos profissionais da Contabilidade sustentam a presente pesquisa, que objetiva analisar o nível de compreensão dos docentes dos programas de graduação de Instituições de Ensino Superior (IES) do Rio Grande do Norte em relação ao conteúdo do Pronunciamento Conceitual Básico (CPC 00).

\section{REFERENCIAL: A CONVERGÊNCIA ÀS NORMAS INTERNACIONAIS DE CONTABILIDADE E O SEU REFLEXO NA EDUCAÇÃO CONTÁBIL BRASILEIRA}

A expansão do mercado financeiro internacional, a crescente globalização dos negócios, a competitividade empresarial, a abertura de capital das companhias e a necessidade por captação de recursos no mercado externo foi o cenário que deu origem à convergência internacional das normas contábeis (Cruz, Ferreira \& Szuster, 2011).

Os objetivos do processo de convergência das normas contábeis estão relacionados com fornecimento de uma melhor compreensão das demonstrações contábeis elaboradas em diversos países, maior facilidade de comunicação internacional no mundo dos negócios com o uso de uma linguagem contábil mais homogênea e redução do custo do capital decorrente da harmonização das práticas contábeis entre os países (Cruz et al., 2011; Coelho \& Lins, 2010; Carpes, Kaveski, Martins \& Klann, 2013).

De forma geral, a harmonização das normas contábeis internacionais abrange as normas e práticas de reconhecimento, mensuração e evidenciação das informações contábeis. Neste momento da convergência a contabilidade não era uma linguagem homogênea em termos internacionais, uma vez que muitos países possuíam as suas próprias práticas contábeis (Fernandes et al., 2011).

A adoção das normas internacionais demanda do profissional contábil a capacidade de realizar julgamentos, uma vez que as IFRS não estabelecem regras rígidas, ao invés disso estabelecem princípios (Chipper, 2003; Carmona \& Trombetta, 2008), sendo essa uma das principais mudanças do processo convergente no Brasil. Será necessária a mudança da concepção de um ensino baseado em regras, orientados para fins fiscais, para uma normatização baseada em conceitos e princípios com foco na essência econômica sobre a forma legal (Machado, Kuhn \& Machado, 2013; Niyama \& Silva, 2013). 
O ambiente acadêmico é palco de diversas transformações, por meio dos avanços da tecnologia, do mercado financeiro e das transformações sociais, os quais influenciam diretamente os meios de acesso à informação e ao conhecimento (Farias \& Araujo, 2016). Nessa perspectiva, a evolução da ciência contábil, da mesma forma que o seu ensino, está diretamente associada ao progresso da sociedade e às transformações do mercado financeiro (Peleias, Silva, Segreti \& Chiroto, 2007; Ribeiro da Silva, 2008).

Antes da convergência das normas internacionais em 2008, o ensino da contabilidade no Brasil, na maioria das vezes, enfatizava os aspectos técnicos da profissão, como o aprendizado da escrituração em observância às regras fiscais para recolhimento de tributos, levando à impressão do aluno e da sociedade que a profissão se restringe apenas às operações rotineiras e cheias de detalhes, desfocando a importância da contabilidade em seu produto final, como na utilização das informações contidas nos relatórios contábeis para o auxílio da tomada de decisão (Marion, 1996; Beck \& Rausch, 2014).

A perspectiva do ensino da contabilidade, baseada no ensino de procedimentos de escrituração, implica na formação de profissionais tecnicistas e vão no caminho inverso às necessidades do mercado, no qual é exigido um profissional que possua pensamento crítico, com conhecimentos alicerçados pelos conceitos contábeis e com uma visão multidisciplinar dos fatos, que possa oferecer uma parceria estratégica nos negócios, orientando os caminhos a serem assumidos pela entidade (Machado \& Casa Nova, 2008; Beck \& Rausch, 2014).

Dessa forma, os docentes assumem um papel substancial e desafiador, o de preparar seus alunos para a realização de julgamentos na aplicação das IFRS e tornar claro para os futuros profissionais contadores a necessidade de o julgamento profissional ser baseado no subjetivismo consciente (Hodgon, Hughes \& Street, 2011).

\subsection{A Estrutura conceitual e o ensino da contabilidade}

Antes da promulgação da Lei $11.638 / 2007$ por meio do qual o Brasil aderiu às normas internacionais de contabilidade, o país possuía dois documentos que determinavam a estrutura conceitual para a contabilidade descrevendo os princípios fundamentais da contabilidade. Eram eles: a Deliberação no 29/86, editada pela Comissão de Valores Mobiliários (CVM) e a Resolução no 750/93, aprovada pelo Conselho Federal de Contabilidade (CFC) (Cruz et al., 2011; Nunes, Marques \& Costa, 2016).

Em 2008, após a aprovação e divulgação pelo Comitê de Pronunciamentos Contábeis do Pronunciamento Conceitual Básico - conhecido como CPC 00, revisado em 2011 - que dispõe sobre a estrutura conceitual para a elaboração e apresentação das demonstrações contábeis, a CVM aprovou esse pronunciamento através da Deliberação CVM no 589/2008 e revogou a Deliberação CVM no 29/86. Entretanto, o CFC não anulou a Resolução CFC no 750/93, emitindo em 2010 a Resolução no 1.282/10 que atualiza os princípios da contabilidade.

Dessa forma, até o ano de 2016, no Brasil, coexistiam duas estruturas conceituais para a contabilidade: o CPC 00 (R1) elaborado pelo CPC e aprovada pela CVM e pelo CFC e a Resolução CFC no 1.282/10 (Nunes et al., 2016). Por fim, em outubro de 2016, o CFC aprovou a Resolução no 1.282/10, tornando assim, a partir de 1 o de janeiro de 2017, o CPC 00 (R1), emitido pelo CPC, a única estrutura conceitual para a contabilidade em vigor no Brasil.

A Estrutura conceitual, pronunciamento, correlato ao Framework for the Preparation and Presentation of Financial Statements emitido pelo IASB, estabelece os princípios que alicerçam as 
estimativas, os julgamentos e os modelos sobre os quais as demonstrações contábeis em IFRS são amparadas (Wells, 2011).

RIAHI-BELKAOUI (2004) ilustram o escopo geral da estrutura conceitual bem como lista e relaciona os documentos emitidos em 1982 pelo FASB.

Figura 1. Escopo geral da estrutura conceitual

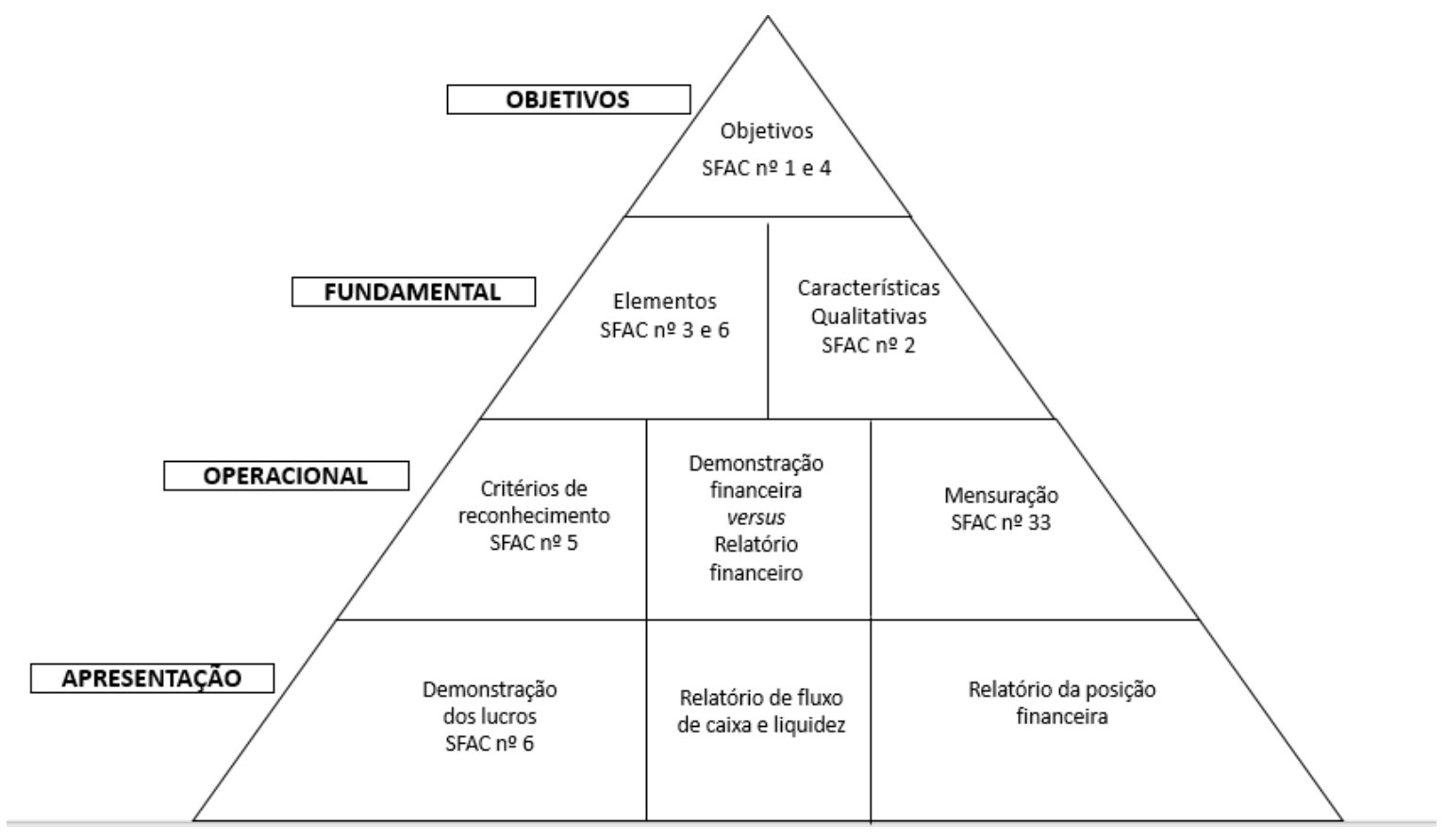

Fonte: Adaptado de RIAHI-BELKAOUI (2004)

A Figura 1 evidencia como a estrutura conceitual fornece a fundamentação para outros pronunciamentos, servindo como base para a compreensão e norteador para elaboração de novos e revisão de pronunciamentos já existentes.

De acordo com Niyama (2010), a existência de um arcabouço teórico expressa que os objetivos da contabilidade e das demonstrações contábeis e possui um alicerce conceitual de padrões e princípios que respalda uma contabilidade apropriada, autônoma e mais resistente às interferências do governo.

Na sua estrutura, o pronunciamento conceitual básico aborda os seguintes itens: o objetivo da elaboração dos relatórios contábil financeiro, os usuários da informação contábil e suas necessidades informacionais, as características qualitativas fundamentais e de melhorias da informação contábil útil, a definição, o reconhecimento e as formas de mensuração dos elementos das demonstrações contábeis, e o conceito de capital e manutenção de capital que orientam a forma de mensurar o lucro de uma entidade (Comitê, 2011).

Wells (2011) preconiza que o ensino da contabilidade deve ter como base a Estrutura Conceitual Básica (EC), devido ao fato desse pronunciamento oferecer aos discentes conhecimentos fixados em conceitos que respaldam as demais normas internacionais de contabilidade. As orientações do pronunciamento conceitual básico têm por finalidade dar suporte à elaboração de novos pronunciamentos técnicos, assim como auxiliar os profissionais contábeis na preparação dos relatórios contábeis financeiros de propósito gerais. 
Dessa forma, o ensino da contabilidade tendo como suporte a EC é capaz de aprimorar a capacidade dos alunos para exercerem os julgamentos necessários para aplicar as IFRS, e da mesma forma instruí-los para uma aprendizagem efetiva (Nunes et al, 2016). Dessa forma, a EC contribui para a elaboração de informações contábeis de alta qualidade e consequentemente para a valorização da profissão contábil.

\section{METODOLOGIA}

A presente pesquisa pode ser caracterizada como descritiva, visto que procura descrever os fatos e fenômenos encontrados. Em relação à sua abordagem, o trabalho é classificado como quantitativo, uma vez que os dados coletados receberam tratamento estatístico, através do qual foi mensurado o nível de compreensão dos docentes acerca da estrutura conceitual da contabilidade, o CPC 00 (R1).

Este estudo busca analisar o nível de compreensão dos docentes integrante dos programas de graduação em Ciências Contábeis. Para tanto, a coleta de dados foi realizada por meio de um questionário estruturado, aplicado de forma online.

O questionário utilizado como instrumento desta pesquisa foi adaptado do estudo de Cruz et al. (2011), tendo sido estruturado em três partes. A primeira parte foi composta por sete questões de classificação (gênero, IES que leciona, cidade onde se localiza a IES, se a Instituição é pública ou privada, tipo de vínculo com a Instituição e em qual área da ciência contábil o professor leciona).

As questões que integravam o segundo e terceiro bloco desse questionário foram caracterizadas pela classificação e proposições da escala Likert, excetuando-se as questões oito e 13. A escala Likert é uma classificação de cinco, sete ou nove pontos em que a atitude do entrevistado é medida sobre uma série contínua que vai de altamente favorável até altamente desfavorável, ou vice-versa, com igual número de possibilidades negativas e positivas de resposta e uma categoria média ou neutra (Rea \& Parke, 2002).

Composto por seis perguntas (variáveis Q8 a Q13), o segundo bloco do questionário versou acerca do nível de conhecimento dos docentes em relação à estrutura conceitual. Os respondentes afirmaram se já haviam lido o referido pronunciamento (sim ou não), se tinham realizado pesquisas sobre o assunto (sim ou não), o grau de pertinência deste assunto para a sua atuação docente (cinco pontos), sobre a importância do CPC 00(R1) para os estudantes ou profissionais contábeis (cinco pontos), a frequência com que o tema era discutido em sala de aula (cinco pontos), e em que medida os professores consideram que têm dedicado tempo para estudo e aprofundamento do assunto (três pontos).

Por fim, a terceira parte do questionário (Q14 a Q23) traz 10 questões que tratam sobre o conteúdo exposto na estrutura conceitual. As proposições possuem uma escala que varia de 1 a 5 - sendo (1) discordo totalmente; (2) discordo; (3) neutro; (4) concordo; e (5) concordo totalmente. Foram atribuídos a esses pontos valores de um a cinco, respectivamente. As proposições possuiam direção positiva e negativa.

Com o objetivo de verificar a compreensibilidade do questionário a ser aplicado foi feito um pré-teste com cinco docentes, que foram escolhidos pela acessibilidade e atestaram a compreensibilidade das questões. Dessa forma, o questionário validado foi enviado aos docentes através do website enquetefacil.com, e também encaminhado para o e-mail dos departamentos dos cursos de Ciências Contábeis de IES do Rio Grande do Norte. O questionário ficou disponível durante trinta dias, no período de 15 de agosto de 2016 até 14 de setembro de 2016. 


\subsection{População e Amostra}

A amostra dessa pesquisa foi constituída pelos docentes que integram os programas de graduação em ciências contábeis das seguintes instituições de ensino superior: Universidade Federal do Rio Grande do Norte (UFRN) - Campus Natal e Caicó; Universidade Estadual do Rio Grande do Norte (UERN) - Campus Mossoró e Patu; Universidade Federal do Semiárido (UFERSA), localizada em Mossoró; Universidade Potiguar (UnP), Unifacex e Uni-RN, localizadas em Natal; e a Faculdade Católica Santa Teresinha, localizada em Caicó, no período de agosto de 2016.

O link com as perguntas foi enviado aos 89 professores, distribuídos entre as instituições citadas. Após o envio do questionário, obteve-se a resposta de 42 docentes. Dez questionários foram descartados por não terem sido respondidos integralmente, ficando 32 para compor a análise, número que representa $36 \%$ dos entrevistados. Ao se aplicar o cálculo amostral com uma confiabilidade de 95\%, a margem de erro destes resultados foi de 13,94\%. Essa porcentagem de resposta pode ser considerada boa, pois segundo Lakatos \& Marconi (2003), no Brasil, a média de devolução dos questionários é de $25 \%$. Para efeito de comparação, o estudo de Cruz et al., (2011) obteve uma porcentagem de $20 \%$ dos questionários enviados.

A maior parte dos respondentes foi da Mesorregião do Leste Potiguar (69,75\%), onde se encontra o maior número de IESs do Rio Grande do Norte. A Mesorregião Central Potiguar e Oeste Potiguar representaram $9,38 \%$ e $21,88 \%$ do total de respondentes, respectivamente. Em relação ao gênero, 13 corresponderam ao gênero feminino e 19 eram do gênero masculino. Após a coleta e a tabulação dos dados, foi realizada a análise estatística.

\section{ANÁLISE DOS RESULTADOS}

Tendo como objetivo analisar o nível de compreensão dos docentes acerca da estrutura conceitual da contabilidade, inicialmente, buscou-se verificar se os mesmos já haviam lido o pronunciamento contábil, qual era a visão deles sobre o grau de importância do pronunciamento para os estudantes e profissionais contábeis e a pertinência do pronunciamento para a atuação do docente.

Na primeira pergunta do questionário foi perguntado aos professores se eles já tinham lido a EC. Das 32 respostas obtidas, 91\% assinalaram que sim, resultado esse que converge com o que indicam Wells (2011) e Cruz et al., (2011) sobre a pertinência da EC para o exercício profissional dos contadores. Este conceito teve seu valor ressaltado para os docentes, uma vez que são esses profissionais os responsáveis pela formação de futuros contadores para atuarem no mercado de trabalho.

Seguindo a perspectiva da relevância da EC para o profissional da contabilidade, as respostas obtidas evidenciam que $53 \%$ dos docentes incluídos na amostra apontam alto grau de pertinência da estrutura conceitual para o exercício profissional do docente, 50\% e 44\%, respectivamente, também atribuem como alta e muito alta a importância do conhecimento da EC para os profissionais contábeis. Esses resultados corroboram com os achados de Cruz et al. (2011) que, em sua pesquisa, constataram que a maioria dos professores entrevistados por ele consideram o tema bastante pertinente, obtendo uma média de 3,63, numa escala de 1 a 5 .

Dessa forma, após avaliar, em nossa pesquisa, que os docentes consideram a EC pertinente e atribuem uma importância alta e muito alta para esse pronunciamento, buscou-se verificar com qual frequência os docentes discutem sobre o pronunciamento em sala. Cinquenta e seis por cento dos professores afirmaram que discutem sobre a EC em sala de aula com uma frequência 
mediana. Nesse sentido, os resultados desta pesquisa foram em sentido contrário aos apontados por Cruz et al. (2011). Segundo os autores, os docentes atribuíram uma frequência de 2,93 novamente numa escala de 1 a 5 - para a discussão da EC em sala de aula, tendo o valor mais frequente sendo 3. Nunes et al. (2016) ao fazerem pesquisa com os alunos destacam que $89,4 \%$ disseram que a EC é discutida em sala de aula.

No que diz respeito ao tempo que os professores dedicam ao aprofundamento dos estudos da EC, 59\% responderam que tem dedicado um nível de tempo médio para esse tema e seu aprofundamento, no qual, mesmo assim, atribuem relevância para sua atuação docente. Esse resultado, novamente, converge com o resultado do estudo de Cruz et al. (2011), em que os docentes da pós-graduação têm dedicado pouco tempo para o estudo sobre a EC.

Quanto à frequência de pesquisas realizadas sobre a EC, dos 32 professores que responderam ao questionário, 69\% não têm produzido investigações sobre o assunto. Novamente, os resultados desta pesquisa se aproximam aos apresentados por Cruz et al. (2011) no qual os autores destacam que apenas $34,8 \%$ tem realizado pesquisas sobre o tema.

No terceiro bloco do questionário, verificou-se que a maior parte dos professores assinalou que "concorda totalmente" ou "concorda" que as demonstrações contábeis, de acordo com o que preconiza do CPC 00 (R1), têm como objetivo fornecer informação acerca da posição patrimonial e financeira da entidade. É possível constatar, ainda, que a maioria dos docentes assinalou que tem o objetivo de "ajudar na tomada de decisão de usuários externos ou internos". Entretanto, de acordo com o referido pronunciamento, as demonstrações contábeis de propósito gerais elaboradas, tendo como base o CPC 00 (R1), têm a finalidade de auxiliar na tomada de decisão dos usuários externos.

A respeito das características qualitativas das demonstrações, 91\% dos entrevistados concordaram e concordaram totalmente sobre Relevância e Representação Fidedigna, enquanto características. Já 50\% apontaram, erroneamente, que Prudência continuava a ser outra característica desse CPC. Esse conceito foi excluído da EC em 2011, visto que sua elaboração tinha como base a neutralidade, divergindo do conservadorismo imbrincado ao quesito da Prudência, em que ativo e valor passivo deveriam ser representados pelo seu menor valor.

Carvalho e Salotti (2013), ao estudarem o impacto das normas internacionais no ensino da contabilidade, justificam o número elevado de professores que ainda concordam com a Prudência enquanto característica devido à formação que os mesmos tiveram, derivada da filosofia code law (com influência de normas fiscais sobre a contabilidade societária).

Quanto às características qualitativas de Melhoria, foi possível verificar que a maioria "concorda totalmente" que elas são a Comparabilidade, a Verificabilidade, a Compreensibilidade e a Tempestividade. O quesito Essência sobre a forma foi retirado do conceito característica qualitativa na revisão do pronunciamento, se tornando uma premissa básica para a elaboração da EC. Ainda assim, foi possível constatar que os professores dividiram suas respostas entre "concordo totalmente" e "concordo", confluindo para uma análise de que os docentes precisam se atualizar sobre o assunto.

A respeito da compreensão dos docentes acerca do reconhecimento de um ativo, esperase, de acordo com a EC, que além de satisfazer a definição de ativos, o valor seja material para aquela entidade, que tenha probabilidade de ocorrência e que se tenha confiabilidade na sua medida. Dessa forma, evidencia-se que a maioria dos docentes "concorda totalmente" que um item é enquadrado quando for provável que algum benefício econômico futuro venha a ser entregue e tiver um valor que possa ser estimado, corroborando com os quesitos para reconhecimento de um passivo de acordo com a estrutura conceitual, o CPC 00 (R1). 
Sobre a compreensão dos docentes a respeito dos conceitos de manutenção de capital, 21 deles assinalaram que "o capital financeiro (ou monetário) é considerado como a capacidade produtiva da entidade". Essa afirmação converge ao que descreve o CPC 00 (R1) em que "o capital financeiro é considerado como o poder de compra do capital investido", sendo a capacidade produtiva da entidade inerente ao conceito de capital físico. No mesmo sentido, podemos analisar que 21 docentes também responderam que o conceito de manutenção de capital representa um elo entre o conceito de capital e os conceitos de lucro, convergindo com o que divulga a EC.

\subsection{Análise Estatística}

No que diz respeito à análise descritiva, a tabela 2 demonstra que a média do nível de conhecimento foi 121,06 . O valor máximo obtido foi de 137 e o mínimo foi de 92, de uma pontuação máxima de 145 . Ou seja, a média dos docentes representou 83,5\% da pontuação máxima. Considera-se o nível de conhecimento alto, visto que a amostra obteve uma média maior que $50 \%$.

É possível perceber que para a importância do pronunciamento, a média foi de 4,16 com uma moda de 4. Para a frequência de discussão do pronunciamento, a média foi de 3,31 e a moda de 3. Para o tempo de estudo, a média foi de 1,88 e a moda foi de 2 .

Tabela 2 - Estatística descritiva das variáveis dependente e independentes. Rio Grande do Norte, 2017

\begin{tabular}{c|c|c|c|c}
\hline $\begin{array}{c}\text { Variável/Estatística } \\
\text { descritiva }\end{array}$ & Nível de conhecimento & $\begin{array}{c}\text { Importância do } \\
\text { pronunciamento }\end{array}$ & $\begin{array}{c}\text { Frequência de } \\
\text { discussão do } \\
\text { tema }\end{array}$ & Tempo de estudo \\
\hline Média & 121,06 & 4,16 & 3,31 & 3 \\
Moda & 120 & 4 & 0,81 & 2 \\
Desvio Padrão & 10,59 & 3 & 1 & 1 \\
Mínimo & 92 & 5 & 5 & 3 \\
Máximo & 137 & & \\
\hline
\end{tabular}

Fonte: Dados da Pesquisa (2016)

Para analisar a normalidade da amostra foi realizado os testes de Kolmogorov-Smirnov e Shapiro-Wilk, os quais demonstraram uma relação normal entre a variável dependente (nível de conhecimento) e as variáveis independentes: importância do pronunciamento, frequência de discussão do tema e tempo de estudo.

Para avaliar possíveis diferenças de médias quanto à distribuição do nível de conhecimento por região, área de atuação e tipo de ensino e da variável dependente "nível de conhecimento" foi realizado o teste de Kruskal-Wallis. 
Tabela 3 - Resultados do Teste de Kruskal-Wallis para diferença de médias. Rio Grande do Norte, 2017

\begin{tabular}{c|c|c}
\hline Hipótese Nula & Sig & Decisão \\
\hline Distribuição do nível de conhecimento é igual em diferentes tipos de ensino & 0,411 & Aceita-se a hipótese nula \\
Distribuição do nível de conhecimento é igual em diferentes regiões & 0,209 & Aceita-se a hipótese nula \\
Distribuição do nível de conhecimento é igual em diferentes áreas de atuação & 0,227 & Aceita-se a hipótese nula \\
\hline
\end{tabular}

Fonte: Dados da Pesquisa (2016)

Através da tabela 3, observa-se que não existe diferença entre os níveis de conhecimento para diferentes tipos de ensino (público ou privado), para diferentes regiões (regiões do leste potiguar, central potiguar e oeste potiguar) e para a área de atuação do docente (auditoria, contabilidade financeira, contabilidade gerencial, contabilidade governamental, perícia, teoria da contabilidade e contabilidade tributaria).

Para avaliar a relação entre o nível de conhecimento e a importância do pronunciamento, frequência de discussão e tempo de estudo foi feito um teste de correlação entre as variáveis buscando observar se existe alguma correlação entre elas.

Tabela 4 - Coeficiente de Pearson entre a variável Nível de Conhecimento e as variáveis Importância, Frequência e tempo de estudo. $\mathbf{N}=32$ Rio Grande do Norte, 2017

\begin{tabular}{|c|c|c|c|c|c|c|}
\hline Variável & \multicolumn{2}{|c|}{ Importância } & \multicolumn{2}{|c|}{ Frequência } & \multicolumn{2}{|c|}{ Tempo de Estudo } \\
\hline \multirow{2}{*}{$\begin{array}{c}\text { Nível de } \\
\text { conhecimento }\end{array}$} & $\begin{array}{l}\text { Coeficiente de } \\
\text { Pearson }\end{array}$ & Significância & $\begin{array}{c}\text { Coeficiente de } \\
\text { Pearson }\end{array}$ & Significância & $\begin{array}{l}\text { Coeficiente de } \\
\text { Pearson }\end{array}$ & Significância \\
\hline & 0,11 & 0,53 & $-0,12$ & 0,52 & 0,23 & 0,21 \\
\hline
\end{tabular}

Fonte: Dados da pesquisa (2016)

Através da tabela 4 podemos perceber que a variável dependente (nível de conhecimento) tem correlação positiva com as variáveis de importância do pronunciamento e com o tempo de estudo, porém tem uma correlação negativa com a frequência de estudo. Resultado contrário ao estudo de Cruz et al. (2011) que identificaram uma correlação positiva entre a frequência de estudo e o nível de conhecimento.

\section{CONSIDERAÇÕES FINAIS}

O objetivo desta pesquisa foi mensurar o nível de conhecimento que docentes de programas de graduação do Rio Grande do Norte têm sobre a estrutura conceitual básica, o CPC 00 (R1). O estímulo para a realização desta pesquisa sucedeu-se da premissa de que o ensino alicerçado pela Estrutura Conceitual eleva a capacidade dos alunos de exercerem julgamentos sobre a aplicação prática das IFRS, assim como os prepara para o aprendizado continuado ao longo da carreira de contador (Wells, 2011).

O resultado da pesquisa mostra que o nível de conhecimento sobre a estrutura conceitual é alto, comparando com o resultado obtido por Cruz et al. (2011), visto que a média de acertos 
ficou acima do resultado obtido por Cruz et al. (2011). Apesar do resultado da pesquisa mostrar um nível de conhecimento alto, nota-se também que alguns respondentes assinalaram respostas que com a revisão da estrutura conceitual tornaram-se desatualizadas, levando a acreditar que é necessária uma atualização destes docentes no que diz respeito à nova estrutura conceitual básica.

Apesar de vários resultados convergirem com os da pesquisa de Cruz et al. (2011) cabe ressaltar que o cenário dessa foi o ano subsequente à adoção das IFRS e divulgação do CPC 00 e o nossa pesquisa foi realizada oito anos após tais acontecimentos. Esperava-se, com esse tempo passado, que a estrutura conceitual estivesse mais embasada no dia a dia da atuação profissional docente, bem como de pesquisas acadêmicas.

Outro apontamento a ser destacado é que apesar dos dados em sua maioria serem da região leste potiguar, os dados obtidos das demais regiões (central potiguar e oeste potiguar) não demonstram que existe diferença sobre o nível de conhecimento a respeito da estrutura. Da mesma forma, não se observou diferença quando comparadas as respostas de docentes que ensinam em instituições privadas e públicas e em diferentes áreas de atuação do docente.

Como proposição para pesquisas futuras, acrescentando questionamentos como o tempo de atuação do professor, para que se possa fazer relações com as respostas obtidas. Entende-se, também, a relevância de pesquisar sobre o nível de conhecimento dos discentes acerca dessa estrutura conceitual.

\section{REFERÊNCIAS}

Beck, F \& Rausch, R. B.(2014). Fatores que influenciam o processo de ensino-aprendizagem na percepção de discentes do curso de ciências contábeis, Revista Contabilidade Vista \& Revista, Belo Horizonte, v. 25, n. 2, p. 38-58, maio/ago.

Carmona, S. \& Trombetta. (2008), M. On the global acceptance of IAS/IFRS accounting standards: The logic and implications of the principles-based system. Journal of Accounting and Public Policy, 27(6), 455-461.

Carpes, A.M.S., Kaveski, I.D.S., Martins, J.A.S. \& KlaNN, R.C. (2013), Processo de convergência aos padrões internacionais de contabilidade pelas organizações cooperativas: a percepção dos profissionais contabilistas, Revista de Contabilidade e Controladoria, Curitiba, v.5, n.3, p.114-130, set./dez.

Carvalho, L. N. \& Salotti, B. M. (2013).Adoption of IFRS in Brazil and the Consequences to Accounting Education. Issues in Accounting Education, 28(2), 235-242.

Chipper, K. (2003). Principles-based accounting standards. Accounting Horizons, 17 (1), 61- 72.

Coelho, C. U. F \& Lins, L. S. 2010. Teoria da Contabilidade - Abordagem Contextual Histórica e Gerencial, Atlas, São Paulo.

COMITÊ, D. P. C. (2011). Pronunciamento Conceitual Básico CPC 00 R1/Estrutura Conceitual para Elaboração e Divulgação de Relatório Contábil-Financeiro.

Cruz, C. F., Ferreira, A.C.S. \& Szuster, N. (2011), Estrutura conceitual da contabilidade no Brasil: Percepção dos docentes dos Programas de Pós-Graduação Stricto Sensu em Ciências Contábeis. Revista Pensar Contábil, Rio de Janeiro, v.13, n.50, p.53-63, jan./abril. 
Domingos de Araújo, K., Cornacchione Junior, E. B., Reginato, L., \& da Silva Suzart, J. A. (2014). Percepção dos impactos da adoção das ifrs na contabilidade gerencial sob a ótica dos professores de programas de pós-graduação stricto sensu em contabilidade. Revista Universo Contábil, 10(2).

Espejo, M. M. S. B, Costa, F., Espejo, R. A \& Comunelo, A. L. (2010). Evidências Empíricas do Ensino no Curso de Ciências Contábeis - Uma Análise das Respostas às Alterações Provenientes da Lei 11.638/07. Revista de Contabilidade do Mestrado em Ciências Contábeis da UERJ (online), Rio de Janeiro, v. 15, n. 1, p. 23 - p. 39, jan./abr.

Farias, R. S \& Araújo, A. M. P.(2016). Percepção dos professores de contabilidade quanto aos espaços formativos para o ofício da docência no Brasil, Rev. Contabilidade e Organização. v.10. N.28, p.58-70,Ribeirão Preto, set./dez.

Fernandes, B. V. R., Lima, D. H. S., Vieira, E. T \& Niyama, J, K. (2011). Percepção de docentes de cursos de graduação em ciências contábeis sobre a função e atuação do comitê de pronunciamento contábeis. Revista Universo Contábil, Blumenau, v.7, n.4, p.60-81, out. /dez.

- Análise da Percepção dos Docentes dos Cursos de Graduação em Ciências Contábeis do Brasil quanto ao processo de convergência as normas interacionais de contabilidade aplicadas no Brasil. Revista de Contabilidade e Controladoria, Universidade Federal do Paraná, Curitiba, v. 3, n.3, p 24-50, set./dez.

Frezatti, F., Braga de Aguiar, A., \& Guerreiro, R. (2007). Diferenciações entre a contabilidade financeira e a contabilidade gerencial: uma pesquisa empírica a partir de pesquisadores de vários países. Revista Contabilidade \& Finanças-USP, 18(44).

Gil, A. C. (2006). Didática do ensino superior. São Paulo: Atlas.

Gilio, L., \& Afonso, L. E. (2013). Grau de aproximação entre a Contabilidade Gerencial e a Contabilidade Financeira em função de convergência às normas do IASB. Contabilidade, Gestão e Governança, 16(3).

Hodgon, C., Hughes, S. B. \& Street, D. L. (2011). Framework-based teaching of IFRS judgements. Accounting Education, 20(4), 415-439.

Jackling, B., Howieson, B. \& Natoli, R. (2012). Some implications of IFRS adoption for accounting education. Australian Accounting Review, 22(4), 331-340.

Lakatos, E. M., \& Marconi, M. D. A. (2003). Fundamentos da metodologia científica. In Fundamentos da metodologia científica, São Paulo: Atlas.

LOPES, A. B. (2011). Teaching IFRS in Brazil: News from the front. Accounting Education, 20(4), 339-347.

Machado, V. S. A., Casa Nova, S. P. C. (2008). Análise comparativa entre os conhecimentos desenvolvidos no curso de graduação em contabilidade e o perfil do contador exigido pelo mercado de trabalho: uma pesquisa de campo sobre educação contábil. Revista de Educação e Pesquisa em Contabilidade, v.2, n.1, p.1-23, jan./abr.

Machado,L.S., Kuhn, J. \& Machado, M.R.R.(2014),Conhecimento dos docentes de contabilidade sobre as normas internacionais, Revista de Contabilidade e Controladoria, Curitiba, v.6, n.1, p.28-42, jan./abr. 
Marion, J. C. (1996), Contabilidade Básica, São Paulo: Atlas.

Niyama, J. K, \& Silva, C.A.T. (2013). Teoria da Contabilidade, São Paulo: Atlas.

Niyama, J. K. (2010), Contabilidade Internacional, São Paulo: Atlas.

Nunes,I.V., Marques, A.V.C. \& Costa, P.S.(2016), Nível de conhecimento dos discentes em ciências contábeis sobre o pronunciamento conceitual básico, Revista Universo Contábil, Blumenau, v. 12, n. 1, p. 87-104, jan./mar.

Pavione, C.S.S.N., Avelino, B.C., Francisco, J.R.S. (2016), Fatores que Influenciam o Processo de Ensino-Aprendizagem sob a Perspectiva de Estudantes do Curso de Ciências Contábeis: Análise em uma Instituição de Ensino Superior de Minas Gerais - Revista de Educação e Pesquisa em Contabilidade, Brasília, v.10, n. 2, art. 5, p. 196-219, abr./jun. 2016

Peleias,I.R., Silva,G.P., Segreti,J.B. \& Chiroto,A.R.(2007), Evolução do Ensino da Contabilidade no Brasil : Uma análise Histórica.R.Cont. Fin, São Paulo, Edição 30 Anos, p.19-32.

Rea, L. M.; Parker, (2002). R. A. Metodologia de pesquisa: do planejamento à execução. São Paulo: Pioneira Thomson Learning.

RIAHI-BELKAOUI, Ahmed. Accounting theory. Cengage Learning EMEA, 2004.

Silva, C. R. (2010), Metodologia da Pesquisa Aplicada à Contabilidade, São Paulo: Atlas.

Wells, M. J. (2011). Framework-based approach to teaching principle-based accounting standards. Accounting Education, 20(4), 303-316,

Wirtanen, J. (2009). The influence of IFRS implementation on business management in Finnish Born Globals. Master's Thesis in Accounting. Helsing School of Economics, 2009 